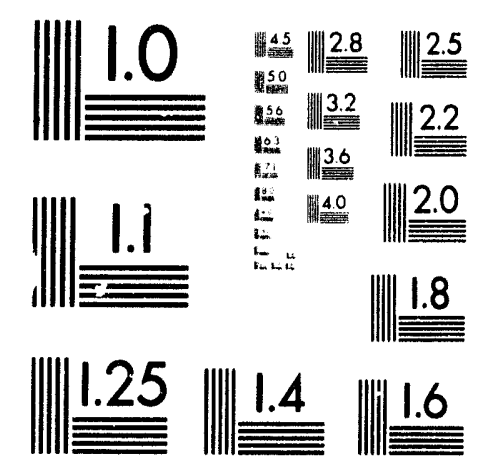



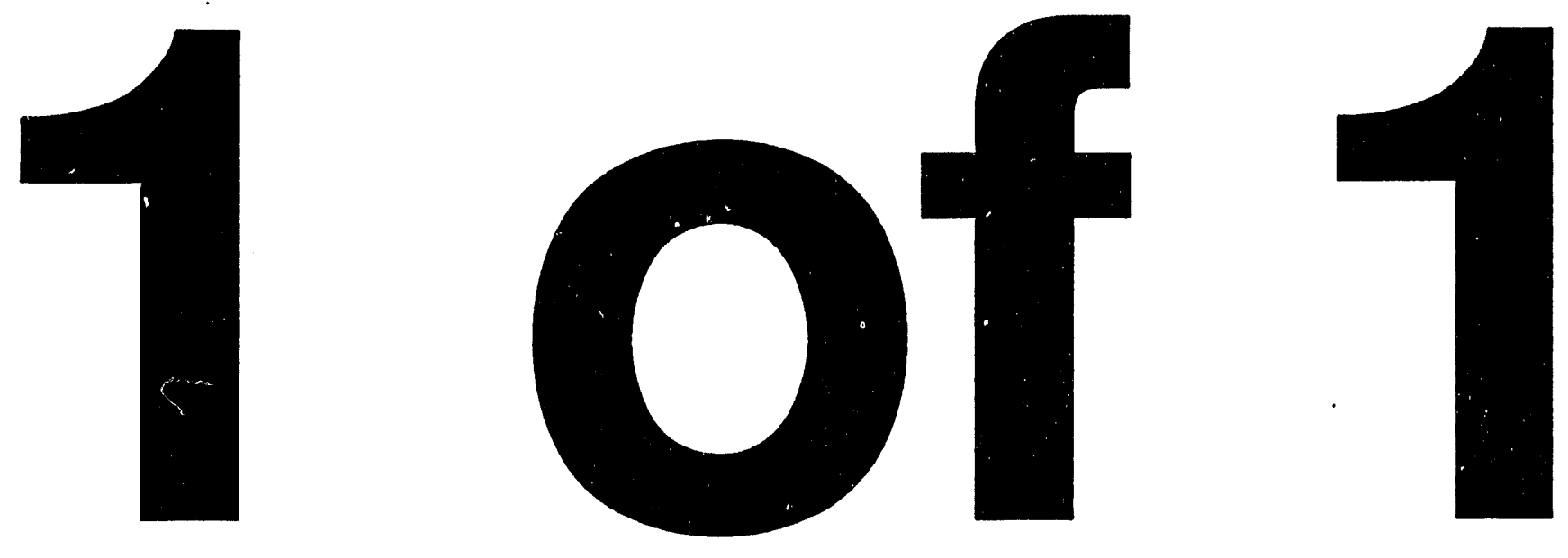
Hans Ludewig, Michael Todosow, and James R. Powell

Brookhaven National Laboratory

Department of Advanced Technology

Building 475B

Upton, New York 11973

(516) $282-2624$

CAMERA READY MANUSCRIPT prepared for:

Eleventh Symposium

on Space Nuclear Power and Propulsion

Albuquerque, New Mexico

09-13 January 1994

initial submission: 21 June 1993

final submission: 1 October 1993

Author to whom correspondence should be sent: Hans Ludewig

Brookhaven National Laboratory

Building 130

Upton, New York 11973

\section{DISCLAIMER}

This report was prepared as an account of work sponsored by an agency of the United States Government. Neither the United States Gnvernment nor any agency thereof, nor any of their employees, makes any warranty, express or implied, or assumes any legal liability or responsibility for the accuracy, completeness, or usefulness of any information, apparatus, product, or process disclosed, or represents that its use would not infringe privately owned rights. Reference herein to any specific commercial product, process, or service by trade name, trademark, manufacturer, or ctherwise does not necessarily constitute or imply its endorsement, recommendation, or favoring by the United States Government or any agency thereof. The views and opinions of authors expressed herein do not necessarily state or reflect those of the United States Government or any agency thereof.

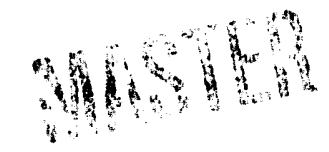




\title{
SMALL LOW MASS ADVANCED PBR'S FOR BI-MODAL OPERATION
}

\author{
Hans Ludewig, Michael Todosow, and James R. Powell \\ Brookhaven National Laboratory \\ Building 130 \\ Upton, New York 11973
}

(516) 282-2624

\begin{abstract}
Ahstract
A preliminary assessment is made of a low mass bi-modal reactor for use as a propulsion unit and as a heat source for generating electricity. This reactor is based on the particle bed reactor (PBR) concept. It will be able to generate both thrust and electricity simultaneously. This assessment indicates that the reactor can generate approximately 6.8 (4) $\mathrm{N}$ of thrust using hydrogen as a coolant, and $100 \mathrm{KWe}$ using a closed Brayton cycle (CBC) power conversion system. Two cooling paths pass through the reactor allowing simultaneous operation of both modes. The development of all the components for this reactor are within the experience base of the NTP project.
\end{abstract}

\section{INTRODUCTION}

The above mission goals imply a reactor which must be able to generate large quantities of power while it is operating as a rocket. The time at high power is short, and thus fuel burnup will be insignificant. However, the fuel and exhaust plenum will have to be compatible with high temperature hydrogen. The electric generation mode of the reactor will require it to operate at relatively low power for years. Fuel temperature during this mode is relatively low, however, the burnup will be high. This burnup level will determine the initial fuel loading.

The mission goals given in Table 1 imply the overall reactor design goals given in Table 2 .

TABLE 1. Mission Goals for Bi-Modal Systems.

\begin{tabular}{|l|c|}
\hline \multicolumn{2}{|c|}{ PROPULSION } \\
\hline Thrust (N) & $6.8(4)$ \\
\hline Specific Impulse (s) & 875 \\
\hline Total Full Power Time (s) & 1500 \\
\hline \multicolumn{2}{|c|}{ ELECTRIC GENERATION } \\
\hline $100 \mathrm{KWe}(600 \mathrm{KWt})(\mathrm{yrs})$ & 6 \\
\hline $30 \mathrm{KWe}(180 \mathrm{KWt})(\mathrm{yrs})$ & 5 \\
\hline Turhine Inlet Temperiture (K) & 1500 \\
\hline Number of restarts & 10 \\
\hline
\end{tabular}


TABLE 2. Reactor Design Goals.

\begin{tabular}{|l|c|}
\hline PROPULSION & \\
\hline Power (MW) & 400 \\
\hline Mixed Mean Outlet Temperature (K) & 3000 \\
\hline Chamber Pressure & 7 \\
\hline ELECTRIC POWER GENERATION & \\
\hline Maximum Fissile Burnup (\%) & 20 \\
\hline
\end{tabular}

\section{Reactor Concept}

The reactor concept used in this design will be the same as the concept used in an accompanying paper (Powell 1994). Thus this paper will concentrate on only the differences between this concept and the propulsion only concept described in the above paper.

Briefly, this reactor concept will retain the four modifications suggested for the propulsion reactor. These are:

Pre-Heater Moderator - Fissile material in Moderator

Hydride Control Device

Afterburner - Fissile Material in Hot Frit

Spike in Hot Frit Duct

In this case though the system must be designed in such a manner that it can operate both as a propulsion reactor (developing $400 \mathrm{MW}$ ), and as a reactor which is part of an electricity generating system. In this case the electricity will he generated using a Closed Brayton Cycle $(C B C)$. The working fluid for the $C B C$ will be helium which is different from the normal coolant (hydrogen) being chemically and neutronically benign. It has been determined that the helium exhaust temperature from the reactor must be $1500 \mathrm{~K}$ for efficient generation of electricity (minimizing the radiator mass). Finally, the reactor needs to generate the electricity for approximately 10 years.

In the proposed PBR design the propulsion mode would operate in a manner identical to that descrihed above. Briefly, the hydrogen would tirst cool the moderator, then the particle bed, and finally the ligt frit. The coolint leaves the reactor through the hot frit duct, and out the nozzle producing thrust. In the CBC mode the coolant (helium) enters the reatctor flows through a special set of ducts in the moderator and then thows on to power the turbine of the $C B C$. The flow direction in this case is axially through the moderator, at right angles to the hydrogen cooling passalges. When the reactor is operating in the electrical mode only, there is no gaseous hydrogen in the moderator. The reactor must thus be critical without the propellant hydrogen in it. Helium gas is expected to have essentially no worth to the reactivity of the core. Heat generated in the hot frit and fuel bed will be conducted to the moderator block where it will be removed by the helium coolant. Thus while the reactor is operating in the $C B C$ mode only the inside of the reactor will be at a pressure corresponding to the vacuum of space, while the components are operating at a maximum of approximately $2000 \mathrm{~K}$. Finally, from this description it is apparent that the moderator must be athle to operate at above $1500 \mathrm{~K}$ for many years. Based on these conditions it is clear that no hydride would be atceptable in the moderator. In fact the only material which can potentially be stable at the projected temperature and still atet as a moderator is graphite. The moderating power of graphite is not as good as that of hound hydrogen and beryllium, thus implying a larger reactor. However, it can easily be loaded with fissile material to the desired loading density (infiltrated method), and it can be coated with a low neutron capture metal carbide coat $(Z \operatorname{rC})$ for protection while it is operating as a propulsion reactor. Since helium is chemically inert all the surfices exposed to helium need not be protected in any special manner. Two possible reactor configurations have been considered, and are shown below: 
TABLE 3. Reactor Core Parameters.

\begin{tabular}{|l|l|l|}
\hline Pitch/Diameter & 2.0 & 2.5 \\
\hline Pitch (cms) & 9.72 & 11.7 \\
\hline Core Height or Diameter (cms) & 48.6 & 58.5 \\
\hline Hot Frit IR (cms) & 1.56 & 1.56 \\
\hline Bed IR (cms) & 1.86 & 1.86 \\
\hline Bed OR (cms) & 2.43 & 2.34 \\
\hline Reflector Thickness (cms) & 7.5 & 5.0 \\
\hline
\end{tabular}

The fissile loading of this reactor must be sufficient to compensate for the fuel burn-up, while generating electricity. Generally propulsion reactors use a very small amount of their fissile material while operating as a rocket, since the burn-up is extremely low. In the mission under consideration this is not the case, and an estimate of the burn-up needs to be made in order to estimate the initial fuel inventory. It is assumed that the reactor will not be serviced during its operating life. It is assumed that the CBC has thermal efficiency of approximately $17 \%$. thus allowing it to reject heat at a relatively high temperature and thus have a relatively small light radiator. The actual CBC unit is a small fraction of the system mass, thus its mass needs not be minimized, rather the entire system inass needs to be minimized. Thus, to generate $100 \mathrm{KWe}$ for 6 years and $30 \mathrm{KWe}$ for 5 years implies a total burn-up of 1640 MWD. If an average bum-up of $20 \%$ is assumed for the intiltrated graphite fuel concept. this would imply an additional $9 \mathrm{Kg}$ of fissile material. The total uranium loading would thus have to be approximately $20 \mathrm{Kg}$ to satisty the mission reyuirements. This material would have to be divided up among the hot frit, fuel hed, and moderator in such a manner, to result in an acceptable temperature distribution under all operating conditions.

In addition, it is elear that only approximately $8 \mathrm{Kg}$ are sufticient to achieve a critical mass in this configuration, thus at the beginning of life (BOL) the excess reactivity must be controlled by external means. In cases such its this, where a large anount of excess reactivity is expected at BOL, and the core is expected to last for many years, a burnable poison is added to the core. The selection of burnable poisons is large such as B-10, Gd, Eu, Ht, and so on, and their distribution within the core is also a variable which can he optimized for maximum core life. In order to make a selection of the "best" burnable poison, and its optimum distribution within the core will require a multi-dimensional burn-up calculation, which can follow the isotopic variations in time and space. The uptimum burnable poison distribution will simultaneously minimize the core mass, and maximize the core life for a given tissile loading. Finally, the poison material cian in principle be added to the graphitic components in the same manner as the fissile material is added to the infiltrated kernels. This technique would allow for spatial variations of the poison distribution.

All the components to be used in this version of the reactor are identical to those described above" for the propulsion only version, except for the moderator. The moderator in this version of the reactor is proposed to be manufactured of graphite infiltrated with fissile material, and the appropriate concentration of burnable poison. It is telt that the development of a graphite infiltrated moderator block will be a simpler task than developing the beryllium based moderator block described above. In summary, the development of all the components for this reator is expected to be simpler and less expensive than for the propulsion only reactor. 


\section{Preliminary Analysis}

The estimated fissile material mass was divided between the moderator, fiuel bed, and hot frit in such a manner that the expected power splits are as shown in Table 4. In addition the resulting coolant outlet temperature and power density of each zone is also shown.

TABLE 4. Operating Parameters for Reactor Design.

\begin{tabular}{|l|c|c|c|c|}
\hline Component & $\begin{array}{c}\text { Power } \\
\text { Fraction }\end{array}$ & $\begin{array}{c}\text { Power } \\
\text { (MW) }\end{array}$ & $\begin{array}{c}\text { Coolant } \\
\text { Temp. (K) }\end{array}$ & $\begin{array}{c}\text { Power Density } \\
\text { (MW/liter) }\end{array}$ \\
\hline Moderator & .375 & 150 & 1290 & 2.155 \\
\hline Fuel Bed & .5 & 200 & 2710 & 28.6 \\
\hline Hot Frit & .125 & 50 & 3000 & 17.4 \\
\hline
\end{tabular}

In order to cool the moderator and hot frit a closely spaced pattern of cooling holes will be required in these two components. Despite the high power density in the particle bed it should be easily cooled, since the heat transter area per unit volume is extremely large ior small randomly packed particles. The following tables summarize results for the three components of concern, in particular the surface temperature of each component is estimated at the inlet and outlet of each zone.

TABLE 5. Parameters for Moderator.

\begin{tabular}{|c|c|c|c|c|c|}
\hline $\begin{array}{c}\text { Diameter } \\
(\mathrm{cm})\end{array}$ & $\begin{array}{c}\text { Pitch } \\
(\mathrm{cm})\end{array}$ & $\begin{array}{c}\text { Unit Area } \\
\left(\mathrm{cm}^{2} / \mathrm{cm}^{3}\right)\end{array}$ & $\begin{array}{c}\text { Gis Temp. } \\
(\mathrm{K})\end{array}$ & $\begin{array}{c}\text { Delta Temp. } \\
(\mathrm{K})\end{array}$ & $\begin{array}{c}\text { Surface Temp. } \\
(\mathrm{K})\end{array}$ \\
\hline .05 & .238 & 3.3 & 35 (inlet) & 1700 & 1735 \\
\hline .05 & .106 & 20. & 1290 (outlet) & 250 & 1540 \\
\hline
\end{tabular}

TABLE 6. Parameters for Fuel Bed.

\begin{tabular}{|c|c|c|c|c|}
\hline $\begin{array}{c}\text { Particle Dia. } \\
(\mathrm{cm})\end{array}$ & $\begin{array}{c}\text { Unit Area } \\
\left(\mathrm{cm}^{2} / \mathrm{cm}^{3}\right)\end{array}$ & $\begin{array}{c}\text { Gas Temp. } \\
(\mathrm{K})\end{array}$ & $\begin{array}{c}\text { Delta Temp. } \\
(\mathrm{K})\end{array}$ & $\begin{array}{c}\text { Surtice Temp. } \\
(\mathrm{K})\end{array}$ \\
\hline .05 & 79 & 1290 (inlet) & 165 & 1455 \\
\hline .05 & 79 & 2710 (outlet) & 75 & 2785 \\
\hline
\end{tabular}

TABLE 7. Parameters for Hot Frit.

\begin{tabular}{|c|c|c|c|c|c|}
\hline $\begin{array}{c}\text { Dia. } \\
(\mathrm{cm} .)\end{array}$ & $\begin{array}{c}\text { Pitch } \\
(\mathrm{cm} .)\end{array}$ & $\begin{array}{c}\text { Unit Area } \\
\left(\mathrm{cm}^{2} / \mathrm{cm}^{3}\right)\end{array}$ & $\begin{array}{c}\text { Gas Temp. } \\
(\mathrm{K})\end{array}$ & $\begin{array}{c}\text { Delta Temp. } \\
(\mathrm{K})\end{array}$ & $\begin{array}{c}\text { Surface Temp. } \\
(\mathrm{K})\end{array}$ \\
\hline .025 & .0532 & 40. & 2710 (inlet) & 185 & 2895 \\
\hline .025 & .0532 & 40. & 3000 (outlet) & 145 & 3145 \\
\hline
\end{tabular}


The above preliminary results indicate that it is possible to cool the moderator, and to keep the implied thermal stresses, due to thermal gralients, within acceptabl .imits. This is because the unit area is lower at li.e inlet end, which reduces the heat transfer efficiency, and thus increases the film drop increasing the surface temperalure. The increased surface temperature reduces the temperature gradient in the solid, which reduces the implied thermal stress. Furthermore, the extremely efficient heat transfer in the particle bed ensures that the solid components all stay within acceptahle thermal limits. Finally, the heat transfer in the hot frit is arranged to be efficient enough to remove the heat while maintaining acceptable temperatures for graphite. In addition the hole size and arrangement is such as to contain the particle bed.

A mass breakdown for the reactor with a fuel element pitch/diameter of 2.5 is shown below. All the masses are given in $\mathrm{Kg}$.

TABLE 8. Mass Breakdown.

\begin{tabular}{|l|c|}
\hline Component & Mass $(\mathrm{Kg})$ \\
\hline Fuel Bed & 22.8 \\
\hline Moderator & 191.8 \\
\hline Frits and Spike & 9.4 \\
\hline Grid Plates & 51.0 \\
\hline Reflector & 114.0 \\
\hline Total & 389.0 \\
\hline
\end{tabular}

This preliminary result indicates that the reflector and moderator are the heaviest components, and any optimization study should consider these as prime candidates for mass reduction.

\section{FUTURE WORK AND CONCLUSIONS}

The activities associated with this design are similar to those outlined for the propulsion only system. An additional task needs to be added in this case, and that concerns the development of an optimum humable poison distribution for maximum life and minimum weight.

The conclusions which can be drawn from these thoughts on a bi-modal system are:

1. A critical reactor configuration can be designed, and optimized. However, the work still needs to he carried out in order to ohtain the precise value of ke, and its variation with burn-up.

2. The development of all the components for this reactor should be well within the experience base of the NTP project, since all the fissile bearing components can be made of intiltrated graphite.

3. Finally, the cost savings described above (Powell 1994) also apply to this reactor concept. The additional sivings related to the simple moderator design should make this version more attratetive.

\section{Acknowledyments}

Reseatrch carried out under the auspices of the U.S. Department of Energy under contract No. DE-ACO2$76 \mathrm{CHO0016.}$ 


\section{$\underline{\text { References }}$}

Powell, J.R., M. Todosow, and H. Ludewig (1994) "Small Low Mass Advanced PBR's for Propulsion, " in Proc. Symposium on Space Nuclear Power System.s, CONF-940101, M.S. El-Genk and .M.D. Hoover, eds. American Institute of Physics, New York, AIP Conference Proc. 

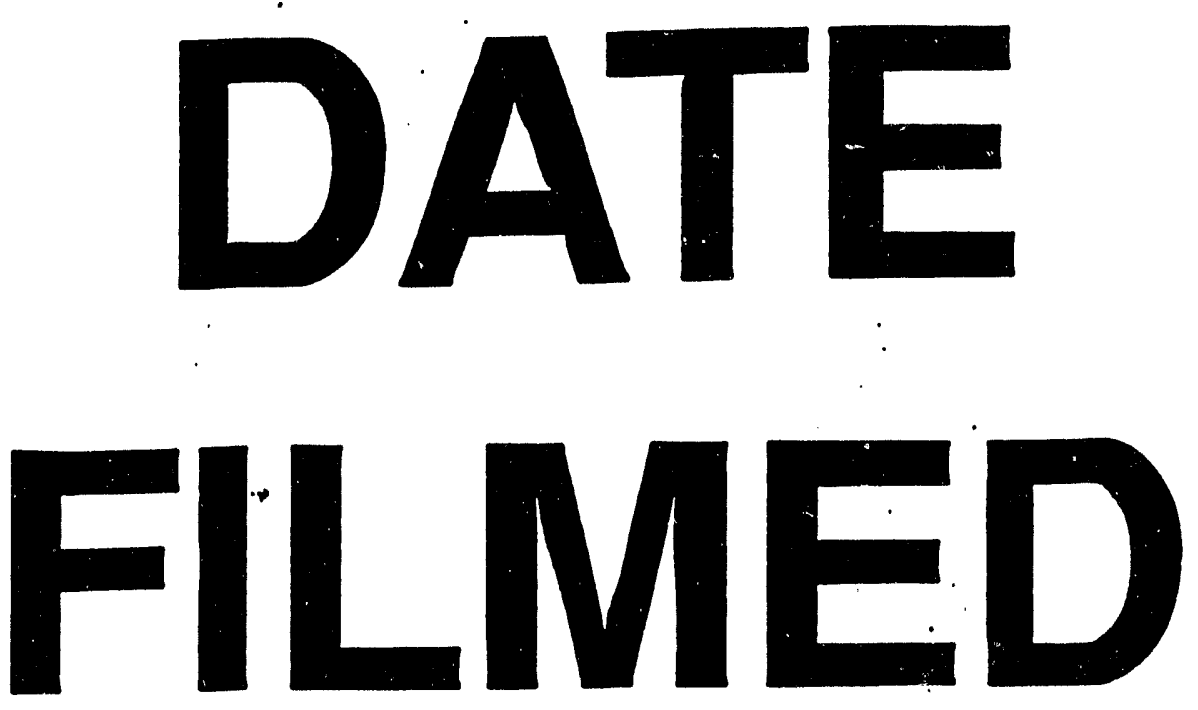

$1 / 26 / 94$
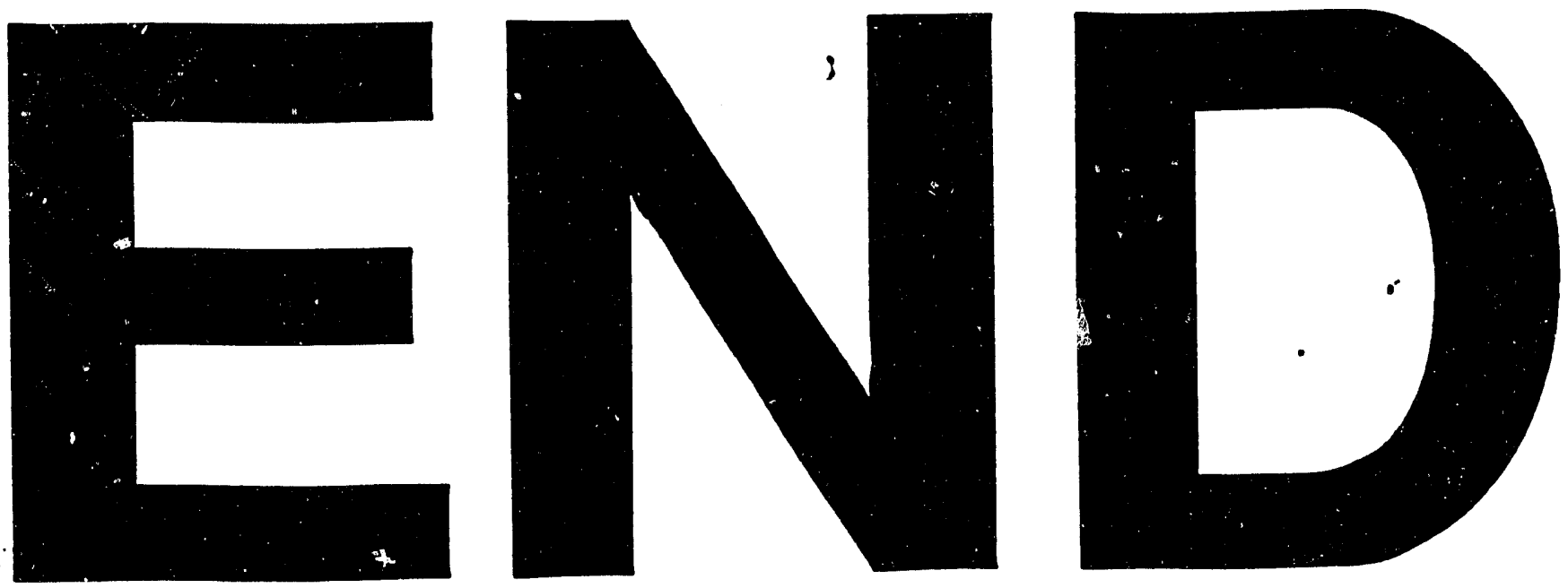
